\title{
Social Housing and Its Pathological Manifastations: A Case Study in Piumhi, Brazil
}

\author{
Tobias Ribeiro Ferreira, Humberto Coelho de Melo, Stella Maria Gomes Tomé, Fernando da Costa \\ Barros \\ Instituto Federal de Minas Gerais Campus Avançado Piumhi, Piumhi, Brazil \\ tobias.ribeiro@ifmg.edu.br; humberto.melo@ifmg.edu.br; \\ stella.tome@ifmg.edu.br; fernando_costabarros@hotmail.com
}

\begin{abstract}
Due to the increase of the deficit of Brazilian social housing in the last years, many actions from public politics were conducted by the Federal, State and municipal governments, as the "My Home My Life" (MCMV) program, considered a solution to reduce the deficit. In Piumhi-Brazil 434 houses were built, where several pathologies were identified in most of the buildings, what contributes to reduce the quality of the life of the inhabitants. This research aims to study the quality of the buildings and presents a proposal of an initial BIM model of a building. This proposal sets an architectonic design that reaches criteria of housing, accessibility and sustainability. 273 houses were visited in 6 different housing estates in the municipality, what enabled to evaluate the conditions of the buildings. Based on the evaluation of questionnaires an architectonic design was developed considering the basic requirements from the inhabitants, updating the proposal of the standard constructed, using the software Revit for a 3D model. It is expected that the model proposed contributes to reduce the pathologies and to increase the quality of the buildings.
\end{abstract}

Keywords: Pathological Manifastations, Social housing, Piumhi-Brazil.

\section{Introduction}

In order to mitigate the housing deficit in Brazil and provide urban housing for the low-income Brazilian population, social housing programs were created to promote the inclusion of urban housing, assuring the well-being of these families through an adequate infrastructure.

The Minha Casa Minha Vida (MCMV) program was created in 2009 guided by the initiative of the Federal Government to reduce housing deficit, being proposed acceptable conditions with minimum standard of sustainability, safety and habitability.

Investments in housing projects of social interest are focused on the social inclusion as well as in the development of the country, by reducing the social inequality of families that do not live in their own house or live in a precarious one. However, it is worth to mention that the MCMV program has not always achieved the objectives hoped, seeing that, most of the time, the social housing are often built on large plots of low economic value and low construction quality, being away from urban areas without basic health services, schools, trades and transport.

In a recent study published by the magazine Mercado da Construção, it was pointed out that over eight completed years in 2017 of the MCMV program, many property owners started to complain about the construction defects, as well as the low quality of the units built in several cities in the country. Regarding the units built between 2011 and 2014, which were distributed in 110 municipalities and 20 states in Brazil, it could be identified construction defects in 336 projects (93,000 housing units) of the properties corresponding to the MCMV program, and the problems were cracks $(30.8 \%)$ infiltration (29\%), leaks (17.6\%) and problems related to coverage $(12.3 \%)$ [1].

For the construction of social housing, the Federal Government has fostered a partnership with the Government of the State of Minas Gerais by creating the COHABMINAS (Housing Company of the State of Minas Gerais) involved in the design and execution of regional and urban policies. In order to promote and facilitate access to housing for the population, the standardized social housing allowed the reduction of housing prices and increasing the supply of new social housing. By developing a partnership in city halls, the municipality provides urban areas and the company promotes the construction and inspection of the work. 
The predominance of masonry and concrete structures in the construction of social housing raises housing costs by using labor and heavy materials that increase the weight of the structures, and also generating debris that are discarded in open dumps. The poor quality of the materials used, inadequate storage at the construction site, as well as the lack of qualification of the workforce directly impacts the life cycle of the buildings.

The characteristics of the houses may be determined by the place where they habe been located, and the elements that are produced for social housing must be done according to the average number of people that are part of the family nucleus, as well as the materials used in the construction must be available and fit for the climate of the region.

According to the Instituto Brasileiro de Geografia e Estatística (IBGE) [2], a Brazilian information agency (2019), the estimated population for Piumhi in 2019 was about 34,525 inhabitants, and its Municipal Human Development Index (MHDI) was 0.738, whereas the Gross National Product (GNP) was estimated in USD 5251.35 (data obtained on November 26th, 2019). In 2010, Piumhi has added 10,646 permanent private housing, 2,575 dwellings as rented properties, 6,858 have their own property and for 727 , the private housing were being acquired.

Regarding an increase of critical problems in civil construction, this study aimed to analyze the quality of social housing in the municipality of Piumhi-Brazil, in order to evaluate if it converges to what happens in the country, which meets the housing requirements requested by residents, thus optimizing the construction processes at an affordable cost, generating information for assessing the useful life of buildings.

The importance of this study aimed to provide an assessment of the conditions of the 436 houses from MCMV program in the municipality of Piumhi-Brazil, in order to propose the solution to these problems, and this way, seeking to new alternatives for housing construction through new techniques and buildings being focused on sustainability, low production cost, guaranteeing habitable conditions for the users and functionality of the building.

\section{Methodology}

For the development of the present work, bibliographic and field researches were implemented. This research was divided into three parts: 1) literature review; 2) diagnosis of social housing pathological manifastation and; 3) development of a preliminary project for social housing in the REVIT software. This work presents the results from the first stage to the third stage, including the elaboration of a preliminary project scope of social housing.

In addition to viewing literature research, it was possible to obtain prior knowledge for the elaboration of questionnaires to be applied for housing residents, as well as to define the strategies for approaching the families that live in these homes. According to Roméro and Ornstein [3], the definition of Post Occupancy Evaluation (POE) consists of a series of methods and techniques, in other words, it is a process of obtaining positive and negative factors in the environment after the occupation, considering socioeconomic factors, urban infrastructure and superstructure of construction systems, environmental comfort, energy conservation, aesthetic and functional factors, for this purpose, the "evaluators" must set a perception perspective of designers, customers and also end users.

For the field research, it was initially defined that 434 houses in the municipality would firstly be visited, which were distributed in six housing estates (Figure 1). In order to analyze the real conditions of social housing in Piumhi and the level of user satisfaction, it was necessary to carry out a post-occupation assessment. Questionnaires were applied to 273 families, corresponding to $62.9 \%$ of households in the municipality, as well as to the photographic records in the actual process regarding the quality of the buildings. 


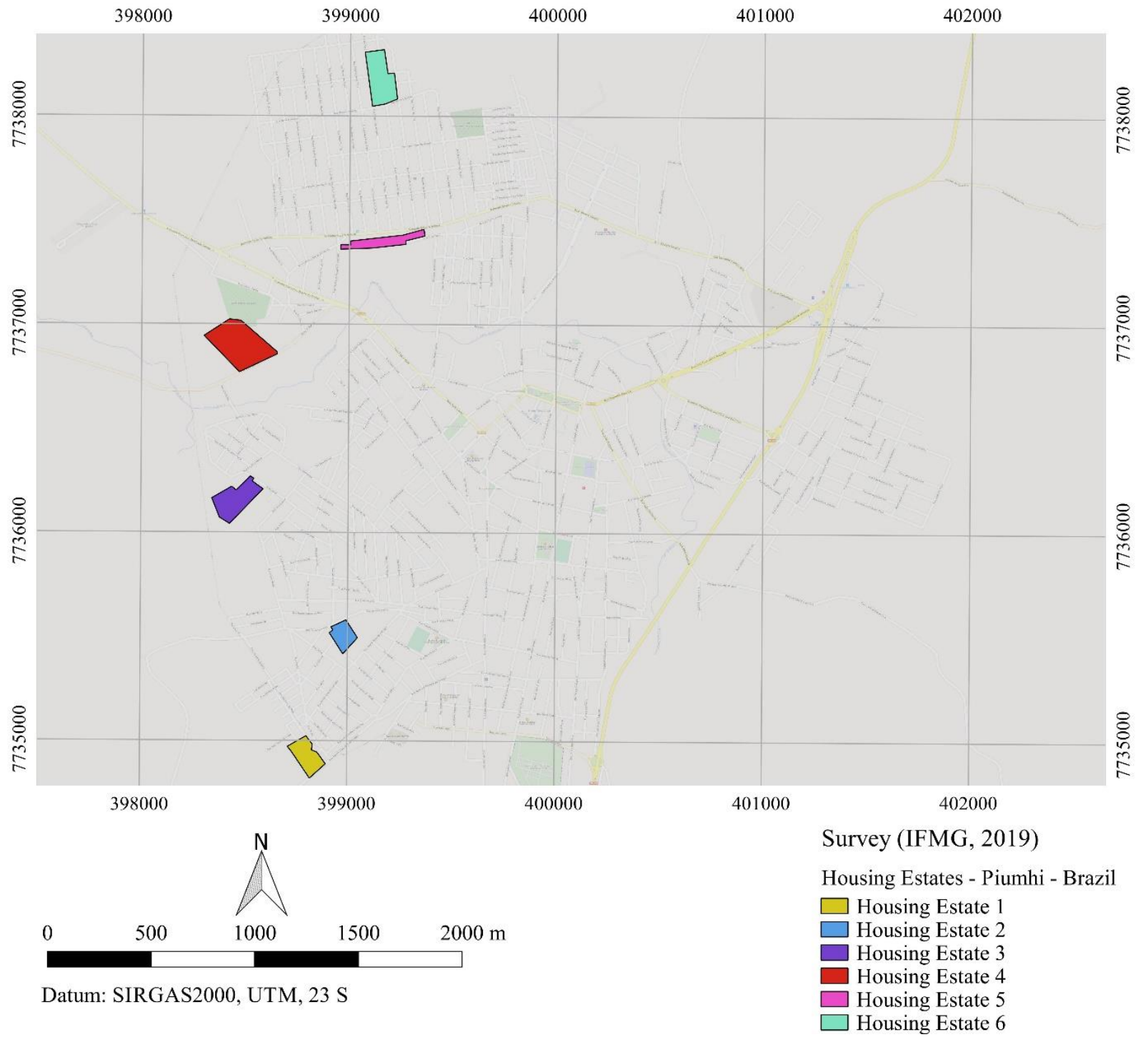

Fig. 1: Social housing distribution in the Municipality.

COHABMINAS is a state agency responsible for providing access to municipal housing and also supplying standardized project models. The standardized models of house was developed to reduce the price of housing in order to provide more social housings (Figure 2). The existing social housing complexes in Piumhi contain a living room, two bedrooms, a kitchen, a bathroom and a service area (single-storey building) (Figure 3). In Brazil, $35.72 \mathrm{~m}^{2}$ correspond to a single family house. 


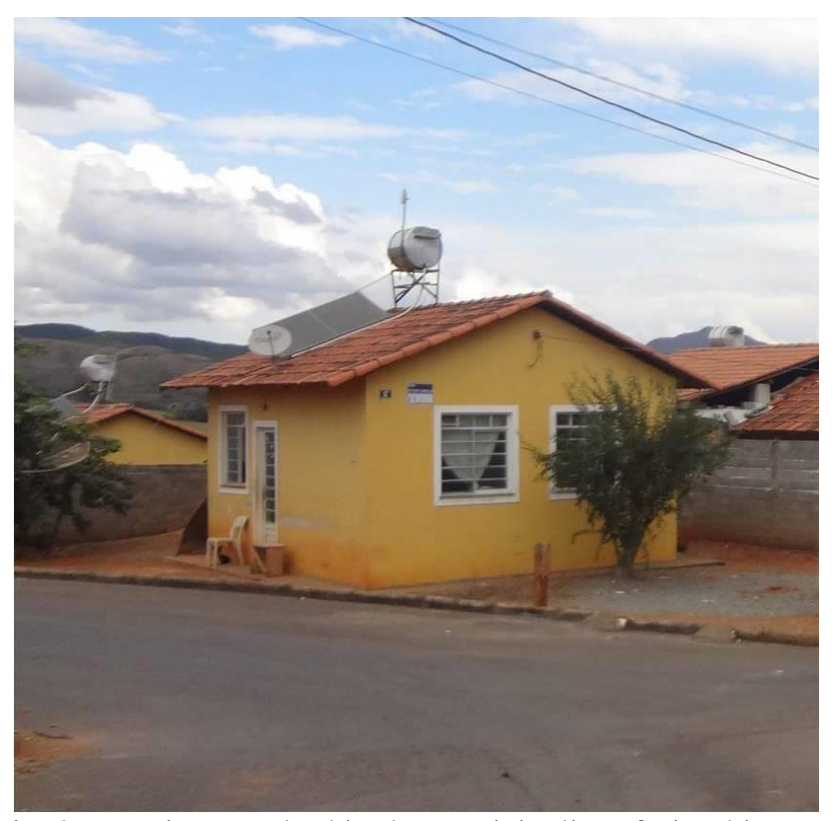

Fig. 2: Housing standard in the municipality of Piumhi - Brazil.

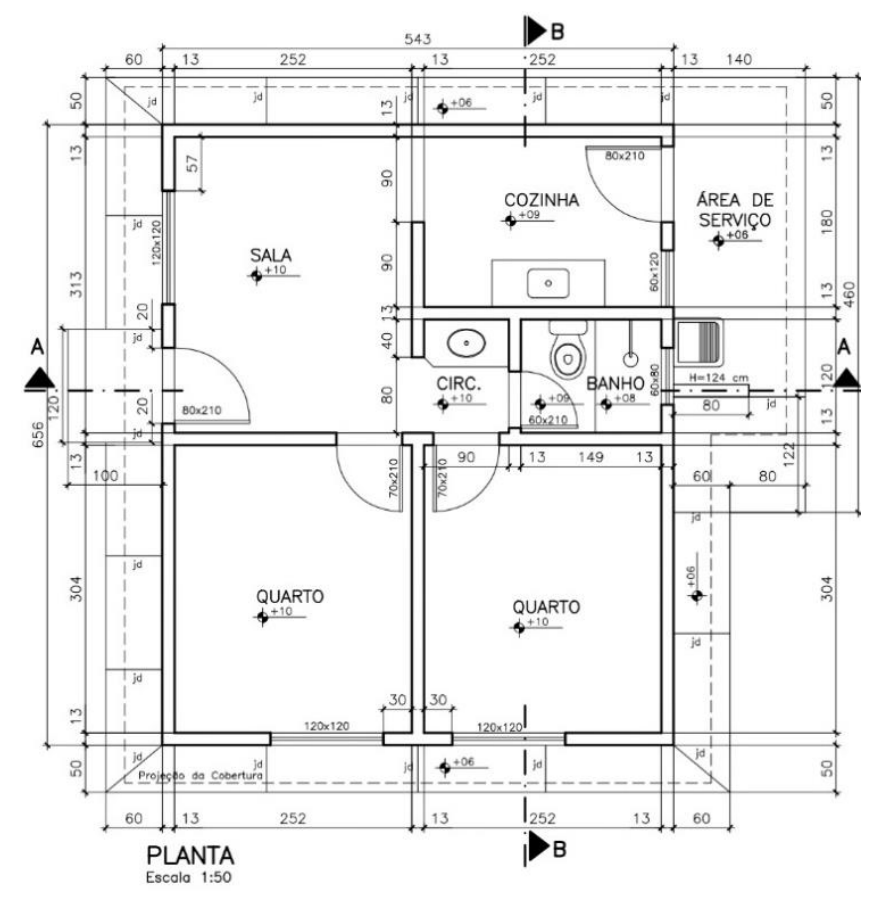

Fig. 3: Housing architecture and design.

The post-occupation assessment of social housing in the municipality of Piumhi was divided into two levels of research. In the first level, data regarding the degree of user satisfaction on building standard were collected, as well as the perceptions of the built environment (construction characteristics, quality of buildings, maintenance, "pathologies"). Concerning the second level, by using visual inspection, photographic records of social housing were made, being possible to evaluate the building elements and functionalities (end activity) of the building, providing an analogy argument based on the performance and accessibility used in these buildings.

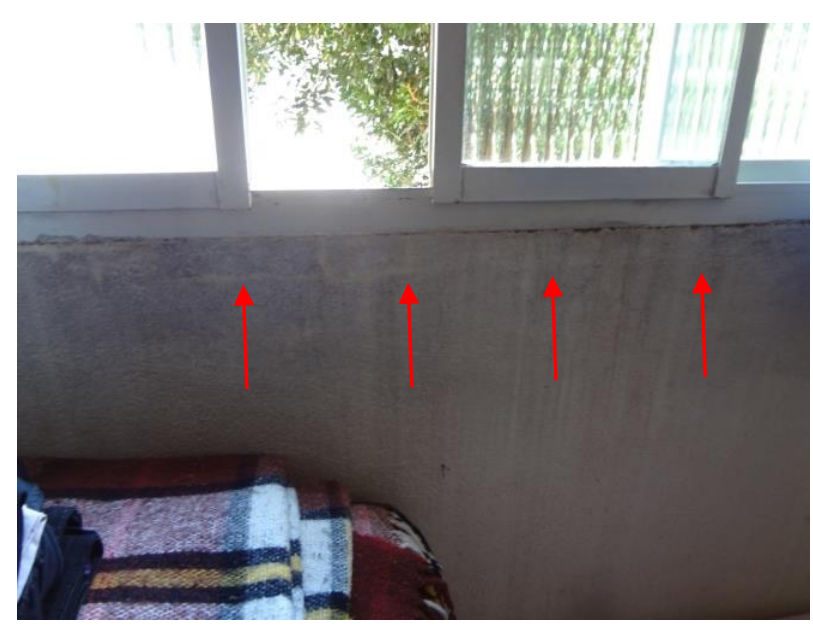

Fig. 4: Recurrent infiltration through the HIS window.

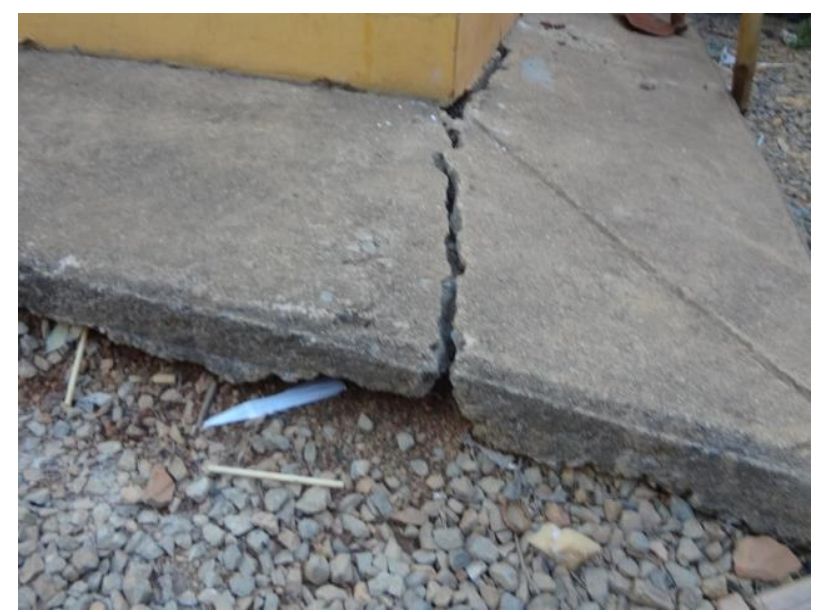

Fig. 5: Cracks in the HIS ride.

Thus, through the collection and tabulation of data in statistics, it was possible to compare the data with the technical evaluation, by proposing interventions at the current project of MCMV program, in order to implement technical guidelines and follow recommendations on social building accompanied by the development of an ideal model of social housing. 


\section{Results and Discussions}

The total amount of social housing provided a sample for the identify the most frequent pathologcal manifestation in Piumhi. About $62.9 \%$ of households were visited, as shown in the table 1.

Table 1: Relationship between the number of social housing in the municipality and the social housing surveyed.

\begin{tabular}{|c|c|c|c|}
\hline Localization & $\begin{array}{c}\text { Year of } \\
\text { Construction }\end{array}$ & $\begin{array}{c}\text { Total amount of } \\
\text { homes }\end{array}$ & $\begin{array}{c}\text { Number of homes } \\
\text { surveyed }\end{array}$ \\
\hline Housing Estate 1 & 2006 & 55 & 33 \\
\hline Housing Estate 2 & 2006 & 46 & 36 \\
\hline Housing Estate 3 & 2006 & 75 & 43 \\
\hline Housing Estate 4 & 2009 & 138 & 83 \\
\hline Housing Estate 5 & 2006 & 60 & 36 \\
\hline Housing Estate 6 & 2010 & 60 & 42 \\
\hline Total & - & 434 & 273 \\
\hline
\end{tabular}

Based on the data collected during the survey, it was noted that $46 \%$ of the families have more than four people inhabited. Therefore, in these cases each dormitory is used by more than one person, implying in a possible discomfort for the two bedrooms homes. In relation to the room sizes, it could be found that $42 \%$ of residents are not satisfied with this size seeing that it is not suitable for people with disabilities, including a member of the family; $23 \%$ of residents are not satisfied with the room size, and when they were questioned about limiting access to other rooms, as well as the circulation inside the building; $62 \%$ of the residents are not satisfied with the kitchen dimensions, being narrow, preventing from more than one family member to go inside.

According to the critical problems (pathological manifastation) of buildings, it was noted that concerning the houses that were built in 2006, water infiltration could be detected in them, making up about $72 \%$, and the most frequent water infiltrations could be found in the window (Figure 4). Approximately $90 \%$ have been facing problems with cracks in sealing masonry or in sidewalks of these buildings (Figure 5). Regarding the data obtained in the interview with the residents, through visual inspection of the dwellings and the analysis of the pathological manifastations in civil construction, a preliminary project was prepared in view of considering the requirements of quality and performance of a housing for the low-income earners.

For the development of the preliminary design, the needs of the residents were taken into account, wherein an attempt to enlarge the rooms requested by the residentes has been managed to accomplish it. A new social housing model was elaborated (Figure 6), measuring $52.08 \mathrm{~m}^{2}$ and containing a living room, two bedrooms, bathroom for people with special needs and a kitchen. 


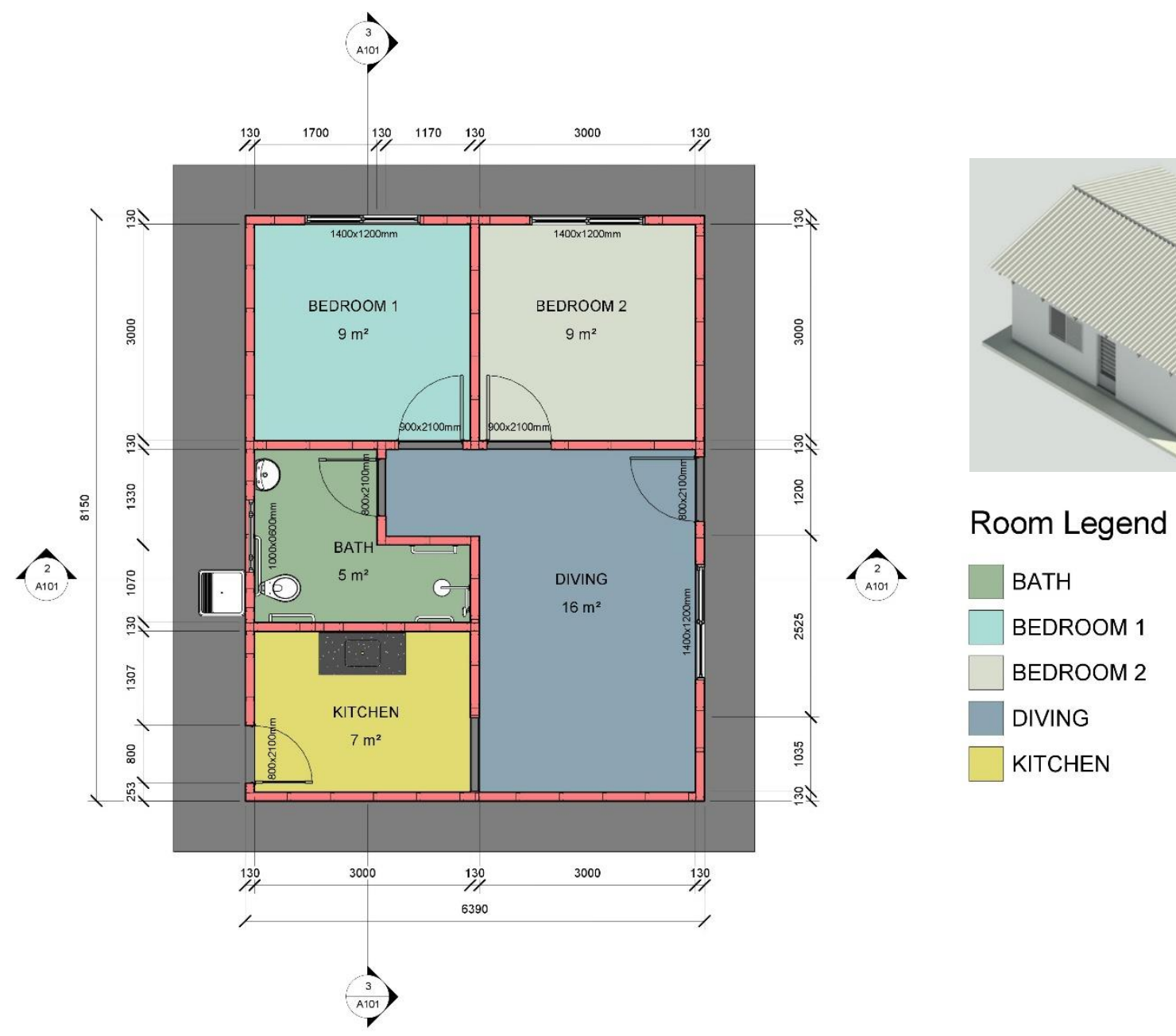

Fig. 6 Project scope of social housing.

\section{Conclusion}

The use of POE has been shown to be efficient for identifying the objectives proposed by the study, furthermore, this tool has been enabled to collect reliable informations to measure and analyze the data obtained.

The profile of the families covered by the social housing in Piumhi (Brazil) is consisted of families of three or four members (54\%), in other words, this profile representes the traditional Brazilian family, including father, mother and one or two children. Therefore, it is necessary to have coherent social housings that adjust to this standard. Few elderly people could be found in these families, nevertheless, for those families, the elderly was a close relative.

The main contributions of this work refer to evaluate the user's perceptions to optimize the design, the operations and to manage information related to construction systems. As a result of the dissemination and evolution of this study, it was emphasized to enhance the importance of quality social housing.

According to the results of the research, they may contribute with new constructive alternatives for the conception of new projects related to HIS that meet the needs of users, as well as with the various agents involved in the process (represented by public authorities, architects, engineers, builders, among others), this way avoiding waste, repairs and rework during their execution and after the end of building project.

Furher studies are strongly recommended to continue monitoring the pathological manifestation in social housing in Piumhi and other cities, what can provide important data to improve the public investments to needed people. 


\section{Acknowledgements}

For the Instituto Federal de Minas Gerais (IFMG) and the Fundação de Amparo à Pesquisa do Estado de Minas Gerais (FAPEMIG).

\section{References}

[1] A. GONSALEZ, "Quase 50\% das moradias do Minha Casa Minha Vida têm falhas de construção". Mercado da Construção, São Paulo, SP, 2017, n.192, pp.24-31.

[2] IBGE 2019 Brasil em Síntese. Sistema agregador de Informações do Instituto Brasileiro de Geografia e Estatística IBGE

[3] M. A. Roméro, S. W. Ornstein. Avaliação pós-ocupação: métodos e técnicas aplicados à habitação social. Porto Alegre, RS: ANTAC, 2003. 